\title{
Do general practitioner deliveries constitute a perinatal mortality risk?
}

\author{
NICHOLAS BLACK
}

\begin{abstract}
In recent years local perinatal mortality experience has been on the agenda of most health district management teams. Nationally available data have been criticised for failing to take into account determinants beyond the influence of existing health services such as lethal congenital malformations. In response to local concern about perinatal mortality rates in Oxfordshire AHA(T) the crude data were refined by using simple epidemiological techniques. This failed to show that a high proportion of general practitioner deliveries constituted a major perinatal risk.
\end{abstract}

\section{Introduction}

The role of epidemiology in the management of health services has been the subject of much discussion. ${ }^{1}$ With the advent of community medicine in 1974 came the hope that the scientific disciplines available to management would increasingly influence decisions. There seem to be two main reasons for what many people believe to have been the relative failure of epidemiology to realise that hope: firstly, the lack of adequate and appropriate routine data and information at a decision-making level, and, secondly, the relative power of overt political factors such as that possessed by groups of clinicians or the treasurer's department compared with the power of evidence derived from scientific inquiries ( $N$ A Black, unpublished observations). This paper looks at these difficulties as they affected the management of maternity services in Oxfordshire-one of the major areas of continuing controversy between the health authority and the community health council.

\section{Background}

The community health council noticed that the crude stillbirth rate, derived from $\mathrm{SH} 3$ returns, for the Banbury consultant unit was almost twice that for the consultant unit in Oxford. Its letter to the health authority criticised the services in Banbury and claimed that expectant mothers were at greater risk there than in Oxford: "We are extremely concerned over the obstetric figures in Oxfordshire, the stillbirth figure for Banbury is alarming" ( $T$ Richardson, personal communication,

\footnotetext{
Department of Community Medicine and General Practice, Radcliffe Infirmary, Oxford OX2 6HE

NICHOLAS BLACK, $\mathrm{MB}, \mathrm{DCH}$, senior registrar in community medicine, Oxford Regional Health Authority
}

1980). The letter went on to suggest that a full inquiry should be held.

These criticisms were answered both privately and publicly by one of the Banbury obstetricians, who pointed out that rates in his consultant unit should not be compared with those in Oxford as a far larger proportion of deliveries in Banbury were carried out by general practitioners. This would have the effect of concentrating high-risk cases in his unit and diluting the case mix in Oxford with low-risk confinements. His public assessment was that, "we can stand up and say we have one of the best, if not the best record in the country." 2 At this stage the issue was taken up by the local community physicians.

Oxfordshire Area Health Authority (fig 1) covers the whole of the county of Oxfordshire except for a small area adjacent to Reading. There are two consultant units along with integrated general practitioner units in Banbury and Oxford and several isolated general practice units. Only statistically insignificant numbers of domiciliary deliveries occur in either population. In the population served by Oxford about $90 \%$ of deliveries take place in the consultant unit, the remainder in the general practitioner units, whereas in and around Banbury only 55\%

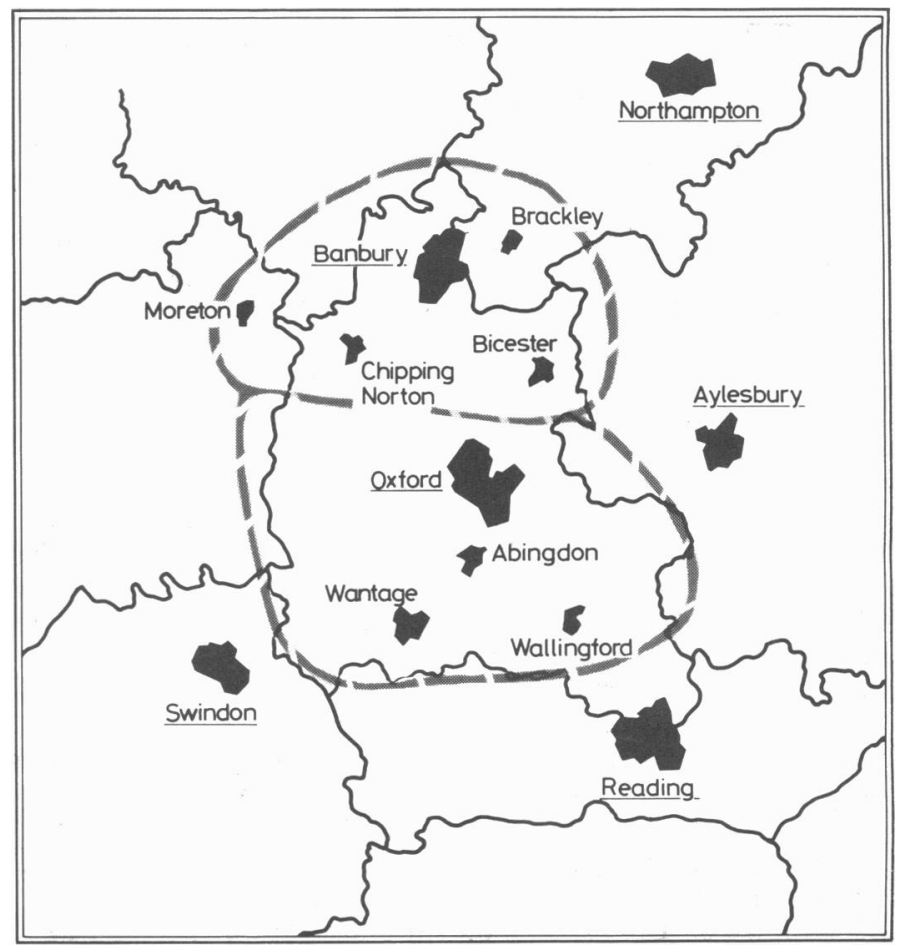

FIG 1-Approximate geographical areas of two catchment populations. 
of deliveries occur in the consultant unit and $45 \%$ in general practitioner units. It is this large proportion of general practitioner deliveries that the Banbury obstetricians were claiming were leaving their consultant unit with a concentration of high-risk cases.

The questions to be answered were whether the perinatal mortality experience in the Banbury catchment population was worse than in Oxford and if so could such a difference be attributed to a high proportion of general practitioner deliveries.

\section{Epidemiological study of local data}

The data that had initially alarmed the community health council were the crude stillbirth rate and later the crude perinatal mortality rate for the consultant unit in Banbury in 1978. Owing to the relatively small number of deliveries annually in each consultant unit the rates showed considerable year-to-year fluctuation but had been following the general decline in England and Wales as a whole. The very different proportions of general practitioner deliveries in the two units required that the first adjustment should be to combine the data for the consultant unit and general practitioner units in each catchment population (fig 2 ). The crude perinatal mortality rates then showed no significant differences, supporting the belief of the Banbury obstetrician that Oxford's consultant unit experienced a dilution by large numbers of low-risk deliveries, who were being confined by general practitioners in Banbury. This was still, however, a comparison of crude rates.

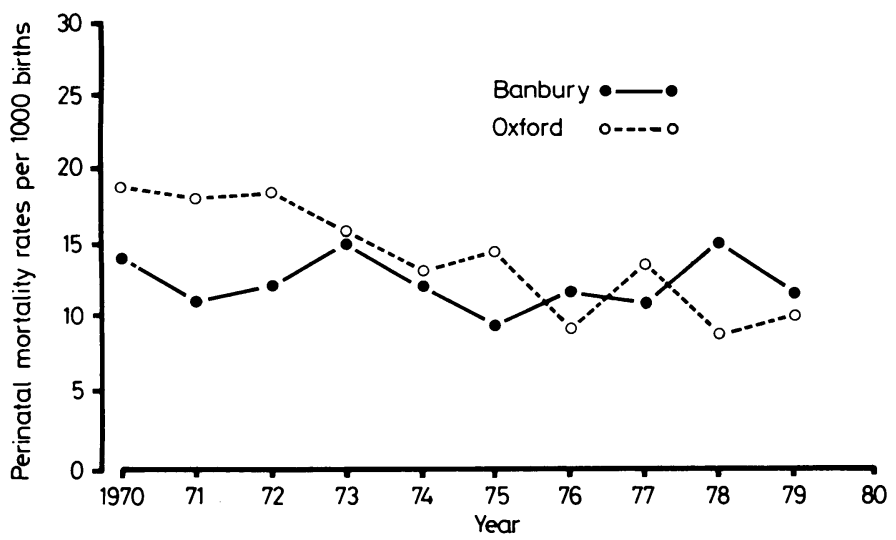

FIG 2-Crude perinatal mortality rates for Oxford and Banbury-consultant and general practitioner units.

The two most significant determinants of perinatal outcome are the presence of lethal congenital malformations and birth weight. ${ }^{3}$ Ideally, it is desirable to have pathological information on all deaths to distinguish those that may be preventable by medical intervention. In the absence of such data it is necessary to use the best available to derive perinatal mortality rates of births free of lethal malformations for specific categories of birth weight.

Birthweight distributions are available from the annual statistical returns to the DHSS from the health authority (LHS 27/1). This showed a decrease in the proportion of low birth weights (under $2500 \mathrm{~g}$ ) in both places over the six years (1973-8) with little difference between the two centres. Data linking birth weight and cause of death for all perinatal deaths are available in Oxfordshire using the Oxford Record Linkage System. The outcome of our calculations (table) showed that there was no statistically significant difference in the birthweightspecific rates during the most recent years (1976-8).

For births over $2500 \mathrm{~g}$ (which accounted for over $90 \%$ of all births) there was no difference in the years 1976-8. The difference in the previous years (1973-5), while not being statistically significant, suggested a better record in Oxford. Similarly, for low and very low birth weights Oxford's results appeared slightly better but, because of the small numbers, these differences were not significant. While these manipulations lead to more appropriate indices for drawing conclusions about the relative safety of different places of delivery, there are still several limitations in this method, which ignores several other factors that may be significant (fig 3). These include the

1 Data (a) Denominator - Ethnicity

- Obstetric intervention policy

(b) Numerator

2 Analysis - Inadequate pathology

- Handling of birthweight distribution

- Statistical significance with small numbers

3 Interpretation

- Considers only mortality

- Actual place of delivery rather than intended place

- Differences a reflection of unit or of staffing

FIG 3-Limitations of approach.

ethnic make-up of the population and the obstetric intervention policies, both of which differ between Oxford and Banbury. In addition, numerator errors are almost certainly present as detailed pathological information is lacking in some deaths, and the information available is subject to observer variation in deeming a malformation lethal. Also births before 28 weeks may survive to become neonatal deaths in some units where in others without intervention they would appear as spontaneous abortions.

Another contentious issue is the handling of birthweight distributions (A J Wilcox, I T Russell, paper presented at 24th annual meeting of the Society for Social Medicine, Cambridge 1980). There are dangers in producing a single statistical indicator, as this may produce bias against the group with heavier weights. Until clearer guidance on an improved technique is available, however, it is necessary for pragmatic reasons to employ birthweight-specific mortality rates. The small numbers of perinatal deaths, even when three consecutive years are combined, limit the power of the analysis. Other difficulties in interpreting the findings include the fact that the only measure of outcome is mortality, with no attempt to consider morbidity or patient satisfaction, and that the information is based on the actual place of delivery rather than the intended place. Lastminute cross-boundary flow of high-risk deliveries may distort the result. Lastly, though we may draw conclusions from the results about the relative safety of different types of units, the differences may reflect the staff within those units rather than any feature of the unit such as its organisation or facilities.

\section{Decision making in health districts}

The Peel Report (1970)4 stated that: "Sufficient facilities should be provided to allow for $100 \%$ hospital delivery. In addition, small isolated obstetric units should be replaced by larger combined consultant and general practitioner units." In 1977 the Labour Government endorsed this view in The Way Forward, ${ }^{5}$ when it spoke of "underused and inefficient

Birthweight-specific adjusted perinatal mortality rates per 1000 total births (actual numbers in parentheses)

\begin{tabular}{|c|c|c|c|c|c|c|c|}
\hline & & & & \multicolumn{2}{|c|}{$1973-5$} & \multicolumn{2}{|c|}{$1976-8$} \\
\hline \multicolumn{4}{|c|}{ Birth weight (g) } & Oxford & Banbury & Oxford & Banbury \\
\hline $\begin{array}{l}\leqslant 1500 \\
1501-2500 \\
>2500\end{array}$ & $\begin{array}{l}\cdots \\
\therefore\end{array}$ & $\begin{array}{l}. \\
\ldots\end{array}$ & $\begin{array}{l}\ldots \\
\cdots\end{array}$ & $\begin{array}{r}464(70) \\
54 \cdot 0(46) \\
2 \cdot 98(41)\end{array}$ & $\begin{array}{r}615(16) \\
60 \cdot 6(12) \\
4 \cdot 11(20)\end{array}$ & $\begin{array}{r}317(44) \\
43.7(36) \\
2.54(35)\end{array}$ & $\begin{array}{r}444(8) \\
60 \cdot 4 \quad(9) \\
2 \cdot 54 \text { (10) }\end{array}$ \\
\hline
\end{tabular}


maternity units being closed." This view was reiterated by the present Government in $1980^{6}$ : "The goal of total provision of maternity care in new district general hospital units," and again in the Government reply to the second report of the Social Services Committee, ${ }^{7}$ when it welcomed the emphasis given by the committee to an increase in the number of deliveries in large units. Evidence that successive governments' guidance has been adopted may be seen in the decline in general practitioner deliveries from around $45 \%$ to under $20 \%$ since the early ' 60 s. ${ }^{8}$

Nevertheless, most studies on place of delivery and perinatal outcome have been unable to show the clear association between general practitioner deliveries and adverse outcome that has been implicitly accepted by successive governments. Fryer and Ashford ${ }^{9}$ considered 50000 deliveries in south-west England between 1956 and 1967 and drew two somewhat surprising conclusions from their analysis relating to birth weight. The first was that higher perinatal mortality rates occurred in consultant units than in general practitioner units for babies weighing over $1500 \mathrm{~g}$; and the second that while the perinatal mortality rate decreased with a progressive increase in the proportion of institutional confinements towards about $75 \%$ any further increases in the proportion led to an increase in mortality rates, particularly for babies weighing over $2500 \mathrm{~g}$. This suggested that there was an optimum proportion for institutional deliveries for any population.

Marsh $^{10}$ analysed his record of obstetrics in his general practice, where $70 \%$ of deliveries were managed by the general practitioners. He found that the crude perinatal mortality rate for his own practice was far lower than that of the United Kingdom. Instead of looking at just one practice Taylor and colleagues $^{11}$ compared three area health authorities with very different proportions of general practitioner deliveries-West Berkshire with $34 \%$, Rochdale and Isle of Wight without any. The overall crude perinatal mortality rate showed little difference. Mortality was grouped into causes, which showed that there was no increased rate in preventable conditions in West Berkshire. To extend this approach further, the mortality experience of babies weighing over $2500 \mathrm{~g}$ has recently been compared with the proportion of general practitioner deliveries for all health authorities in England and Wales ( $M$ Mugford, personal communication, 1981). This shows no correlation between mortality rate and proportion of general practitioner deliveries, though there is a suggestion of a positive correlation if those areas without any general practitioner deliveries are excluded from the analysis.

Yet despite this evidence, the notion that general practitioner deliveries constitute a risk continues to gain support from national guidelines, expert reports, and the opinions of most obstetricians, based largely on belief. Challenging that belief are the results of the research studies and the local statistics, which suggest that although one area, Banbury, has $45 \%$ general practitioner deliveries and the other, Oxford, only $12 \%$, the perinatal mortality rate does not appear to differ for large babies and differs only slightly at low birth weights. How does all this affect the local management decision on service provision?

That decision has to attempt to balance the practicalities of resources with the aspirations and ideals of employees and customers (fig 4). In this particular issue the relevant resources are:

Finance-in which the main factor for discontinuing general practitioner deliveries are the diseconomies of scale, in which
Resources
Limited finance - Economies of scale
Limited staff - Midwives
General Practitioner interest in intrapartum care

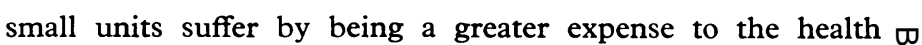
authority (although there has been recent dissent from this view $\left.^{11}\right)$.

Staff-in particular a lack of trained midwives, who are $\frac{2}{c}$ underused in general practitioner units in terms of number of $\widehat{\Omega}$ deliveries performed.

Decline in interest by general practitioners in intrapartum care, partly as a result of diminished opportunities to maintain their $\mathbb{\Phi}$ confidence.

Against such factors are posed the ideals of providing a choice of place of delivery to expectant mothers, and the concept of individuals' rights to decide on their own risk-taking $\stackrel{5}{+}$ behaviour. While the decision maker's approach to risk is to try to gain any improvement however small, it may be that customers perceive risk reduction rather differently. If we assume for a moment that Oxford is a safer place for delivery $\unrhd$ and apply the Oxford perinatal mortality rates to the Banbury क population the chances of a safe outcome irrespective of birth $\vec{P}$

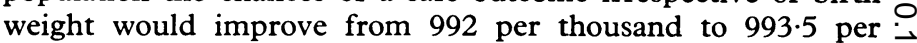
thousand. Many women may consider such an advantage $\vec{\omega}$ insignificant compared with the disadvantages of delivery in a $\stackrel{\circ}{\circ}$ centralised consultant unit.

I thank the staff of the National Perinatal Epidemiology Unit, and $\stackrel{\infty}{\sim}$ in particular Iain Chalmers and Alison Macfarlane, for advice and support in this work. The local analysis would not have been possible $\omega$ without the help of the Oxford Record Linkage Study, and my $\vec{t}$ thanks go to Pam Hughes for typing the paper.

\section{References}

1 Knox EG, ed. Epidemiology in health care planning. Oxford: Oxford Medical Publications, OUP, 1979.

2 Banbury Cake. April 1980.

${ }^{3}$ Chalmers I. The search for indices. Lancet 1979 ;ii:1063-5.

${ }^{4}$ Department of Health and Social Security. Subcommittee of Standing Maternity and Midwifery Advisory Committee. Domiciliary midwifery and maternity bed needs. London: HMSO, 1970:60 (Peel Report.)

${ }^{5}$ Department of Health and Social Security. The way forward. Priorities $\square$ in the health and social services. London: HMSO, 1977.

${ }^{6}$ Department of Health and Social Security. Hospital services. The future pattern of hospital provision in England. London: DHSS, 1980.

${ }^{7}$ Department of Health and Social Security. Reply to the second report from the social services committee on perinatal and neonatal mortality. Cmnd 8084. London: HMSO, 1980.

8 Royal College of General Practitioners. Obstetrics and gynaecology for general practice. $7 R$ Coll Gen Pract 1981 ;31:72-9.

${ }^{9}$ Fryer JG, Ashford JR. Trends in perinatal and neonatal mortality in England and Wales. Br F Prev Soc Med 1972;26:1-9.

10 Marsh GN. Obstetric audit in general practice. Br Med 7 1977;ii:1004-6.

11 Taylor GW, Edgar W, Taylor BA, Neal DG. How safe is general practitioner obstetrics? Lancet 1980 ;ii:1287-9.

(Accepted 7 December 1981)

Once a diagnosis of hypertrophic pyloric obstruction in a baby has been established by barium meal studies and the baby is repeatedly vomiting $\frac{D}{O}$ but can undergo operation under local anaesthesia, should the operation be regarded as an emergency or may the baby be kept for the next routine N list?

While congenital hypertrophic pyloric stenosis may be regarded as a form of alimentary tract obstruction requiring surgical correction, the urgency of treatment is not of the same order as, for instance, the urgency of correcting an incarcerated hernia. The baby has been repeatedly vomiting and will certainly be suffering from dehydration $\tau$ and electrolyte imbalance. Urgent treatment must first be directed to resuscitation and correction of electrolyte and acid/base imbalance; this may take 24-36 hours, during which time gastric lavage may be repeated to empty the stomach of stale curds and relieve the gastritis. A Ramstedt pyloromyotomy is thus not a "middle of the night" operation, and may be planned for the next routine operating list, o provided that a delay of more than 48 hours is not expected.-JAMES LISTER, professor of paediatric surgery, Liverpool. 